\title{
Inaugural Message from the Founding Editor-in-Chief
}

\author{
James Benjamin Aguayo Martel* \\ Clinical Professor of Ophthalmology, California Northstate University College of Medicine, USA
}

The inaugural issue of the New Frontiers in Ophthalmology arrives in a period of history in which the field of Ophthalmology is undergoing innovative and flourishing times. The multifaceted margins of biotechnology, electronics, informatics, analytics, and nanotechnology are rapidly coming to a convergence. With this possible convergence, comes new possibilities of health and wellness. Behind these developments has been the ever present Internet which continues to increase in speed, availability, and growth at nothing short of an exponential rate. Abilities for desktops, laptops, Ipads/tablets, or smartphones to access the Internet has proliferated as well.

More and more physicians are using smartphones for information, action, and content. Computers and cameras have continued to shrink to the level of grains of sand, and with that comes the reality of ocular implants which will not only allow us to improve our vision, but will allow us to see our functional self from an entirely new and continuous level. As we speak, those intelligent grains are being implanted into contacts so as to monitor glucose levels, but other possibilities of what they might be able to monitor are vast and are really only limited by our resourcefulness and our ingenuity. These grains are being placed on eyeglasses which offer us the possibility of augmented realities. Gone are the days of going to a library to hunt for a reference from a bound journal or sending a colleague a manuscript instead of just text messaging the url of the article. These new technologies would allow us to bring up a copy of a study in New Frontiers in Ophthalmology, such as the study on the repair of corneal damage with stem cells by Rodriguez and Vecino, while waiting to board a flight or while writing an article on the use of stem cells to repair skin burns. Of our five senses, the eye is the window to the brain and it is vision that appears to be the most hyperrefined and seated at the center of augmented reality.

Ophthalmological advances continue to achieve new levels of sophistication with the help of new technologies. DNA sequencing makes it possible to determine precise changes in the genetic code, which allows us to observe how these changes may manifest into the disease entities we see in clinical patients. From retinitis pigmentosa to Leber hereditary optic neuropathy, the possibilities of new treatments linger around the corner. New therapies have changed the course of innumerable patients in the areas of infection, glaucoma, and macular degeneration and new surgical approaches have grown at an impressive pace. The accommodative intraocular lens, which was once thought by many ophthalmic surgeons to be beyond the reach of development, is now believed by many to be the implant of choice these days.

We at New Frontiers in Ophthalmology are dedicated to providing the highest quality peer reviewed publications. We will strive for a short turnaround time from submission, to review, to publication that can be easily accessible by anyone who wishes to explore our open knowledge database. Knowledge is boundless, and excellent publications should not be rejected on the basis that there are too many good articles or that a journal is backlogged in reviewing new publications. Open access to information has led to further advances in the scientific knowledge base. It would come as little surprise to me that this process would continue to propagate as I can perceive no limits to human cognition and inventiveness. I believe that knowledge is power, but the power to learn more, help more, achieve more, and to share more with our colleagues around the world.

It was Benjamin Franklin who in 1774, declared that there must be freedom of the press. What I would add to his eloquent words would be the freedom to publish rigorously peer reviewed articles in a rapid turnaround manner and the freedom to have open access to information across all borders around the world.

So it is with the utmost pleasure that I introduce to you the first edition of New Frontiers in Ophthalmology.
Copyright: (C2015 Martel JBA. This is an open-access article distributed under the terms of the Creative Commons Attribution License, which permits unrestricted use, distribution, and reproduction in any medium, provided the original author and source are credited.
Correspondence to: Dr. James Benjamin AguayoMartel, MD MPH FACS, Clinical Professor of Ophthalmology, California Northstate University College of Medicine, 9700 W Taron Drive, Elk Grove, CA 95757, Tel: (916) 6867300, Fax: (916) 6867310, E-mail: james.martel@cnsu.edu

Received: September 22, 2015; Accepted: September 24, 2015; Published: September 26, 2015 